\title{
Comparism of Cure Modeling of Unsaturated Polyester Based Composites Using Microwave and Autoclave Assisted Hand Lay-Up Process in Cylinderical Mould
}

\author{
Adefemi Adeodu ${ }^{1,}$, Christopher Anyaeche ${ }^{1}$, Oluleke Oluwole ${ }^{2}$, Temitayo Azeez ${ }^{3}$ \\ ${ }^{1}$ Department of Industrial and Production Engineering, University of Ibadan, Ibadan, Nigeria \\ ${ }^{2}$ Department of Mechanical Engineering, University of Ibadan, Ibadan, Nigeria \\ ${ }^{3}$ Department of Mechanical and Mechatronics Engineering, Afe Babalola University, Ado-Ekiti, Nigeria \\ Email address: \\ femi2001ng@yahoo.com (A. Adeodu),osita.anyaeche@ui.edu.ng (C. Anyaeche),oluwoleo2@asme.org (O. Oluwole), \\ mrjibs4real@yahoo.com (T. Azeez)
}

\section{To cite this article:}

Adefemi Adeodu, Christopher Anyaeche, Oluleke Oluwole, Temitayo Azeez. Comparism of Cure Modeling of Unsaturated Polyester Based Composites Using Microwave and Autoclave Assisted Hand Lay-Up Process in Cylinderical Mould. Advances in Materials.

Vol. 4, No. 3, 2015, pp. 59-66. doi: 10.11648/j.am.20150403.13

\begin{abstract}
Modeling of composite curing process is required prior to composite production as this would help in establishing correct production parameter and method of curing thereby eliminating costly trial and producing an effective method of curing a particular polymeric composite. The main objective of this work is to compare the difference between modeled microwave and conventional autoclave heating methods in producing polyester-aluminum and polyester- carbon black composites. This will establish the effectiveness of a curing method in the production of a particular polymer composite i. e, prediction of best possible trends during microwave and conventional autoclave heating with regards to effect of heating rate on degree of cure of the composites. The numerical models were constructed by taking into account heat transferred by electromagnetic energy (microwave) and heat transferred by conduction (conventional autoclave) through the resin/filler mixture, as well as kinetic heat generated by cure reaction. The numerical solution of the mathematical models presented were discretized using forward finite differences of the RungeKuta method and finally solved using MATLAB ${ }^{\circledR}$ Computer programming language. It was observed that curing of the samples was achieved faster in microwave than conventional autoclave method as microwave heat transfer by electromagnetic energy produces volumetric heat flow as compared to conventional autoclave whose heat transfer by conduction generates transverse heat flow to the samples. This implies that in the production process of polymer-matrix composites, electromagnetic energy through microwave was able to produce faster heating rate; thus, an effective method of curing in the production process of polymer-metal composites.
\end{abstract}

Keywords: Modeling, Polymer- Matrix Composites, Autoclave Curing, Microwave, MATLABß

\section{Introduction}

In the last decade, the use of composite materials has increased considerably due to their high performance unique features. Composites have found many wide spread applications in modern industries [1]. This increased demand for composites has led researchers in pursuit of better and faster methods of manufacturing composites.

Hand lay-up is a batch manufacturing process used to shape polymeric composite materials into parts with uniform cross-section [2]. This involves the placement of fillers which may be impregnated with resin into an open mould.
The technique is being increasingly employed in the manufacture of filler or fiber-reinforced composite materials, basically due to its design flexibility and low capital cost [3]. Also, offers a potential manufacturing source of high-volume components for aerospace and automotive industries [3].

In the recent time, attention is also focusing on the development of several variants of the hand lay-up process, especially in the area of electromagnetic heating. Such variants include microwave, induction heating and RF heating assisted hand lay-up process. The electromagnetic 
heating assisted hand lay-up is an innovative variant of the hand lay-up process [4], characterized by a high frequency electromagnetic energy source. Electromagnetic heating is a fast instantaneous, non-contact and volumetric heating, and therefore very interesting for material processing [5].

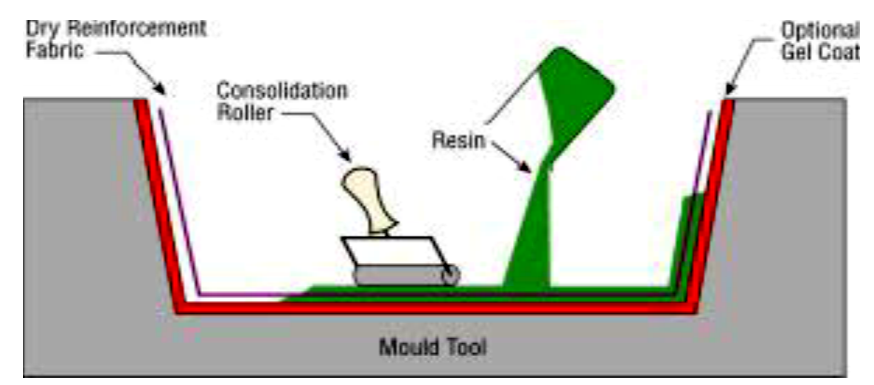

Source: [3]

Figure 1. Schematic diagram of Hand lay-up process.

Polymer-matrix composites fabrication is well served by many continuous and batch processes, all of which share the common and critical step of cure. Cure refers to an irreversible exothermic chemical reaction by which the composite lay-up is transformed from a soft, multi-layered mixture of fillers and resin, to a hard structural component [6]. The high exothermicity of the curing reaction associated with the low conductivity of the material is a feature of fundamental importance. As a result, the curing reaction gives rise to high temperature within the resin especially at the center, and high temperature gradients are developed through the sample [1] [7] [8]. These facts lead to cracking [9-10].

Several numerical modeling and experimental investigations have been performed on different problems related to the hand lay-up process particularly, on the analyses of the rate of heat transfer and degree of cure [1]. The importance of the analyses of the rate of heat transfer and degree of cure in hand lay-up process is highly recognized to obtain a final product characterized by the desired mechanical properties or to realize defects free endproducts. Numerical modeling and simulation of the process of cure is of great importance from a theoretical point of view in order to gain a fuller insight into the nature of the process, and from an experimental point of view, to optimize the operational conditions.

In this study, microwave and autoclave assisted hand layup processing systems for polymer-matrix composites were modeled. Comparison of the structures of the models was also made as an objective of the study.

\section{Materials and Method}

\section{Material Composition}

The proposed models involve evaluating the processing of laminates based on two different polyester mixtures composites A and B. System A consists of an othophthalic type, thermosetting (M3903) polyester resin. The composite based on slurry with the following typical parts by weight [1] $25 \%$ propylene glycol, $25 \%$ phthatic anhydride, $16 \%$ malic anhydride, $38 \%$ styrene monomer and 2\% additive making $100 \%$ unsaturated polyester resin, inert and reinforcing fillers with $30 \%$ of aluminum powder material.

In system $\mathrm{B}$, same composition as in system $\mathrm{A}$ is maintained with the exception of aluminum which is totally replaced by N762 carbon -black of same composition as in system A.

The following are the set of sequential steps that would be used for making hand lay-up Aluminum and Carbon blackPolyester resin composites.

1. The fabricated moulds are properly prepared and clean

2. Correct amount of fillers (Aluminum and Carbon black) are weighed into containers

3. Correct amount of polyester resin, hardener and other additives are weighed and mixed together

4. Resin and filler are evenly and slowly mixed with the aid of mechanical blender inside a fume cabinet (for safety) in order to ensure a homogeneous composite mixture

5. Each mixture is poured into moulds and transferred into the oven. Note, before pouring the mixture into the mould, plate surface would be covered with a glossy paper to facilitate easy removal of the final product after solidification [11] [12] [13].

\section{Process Model}

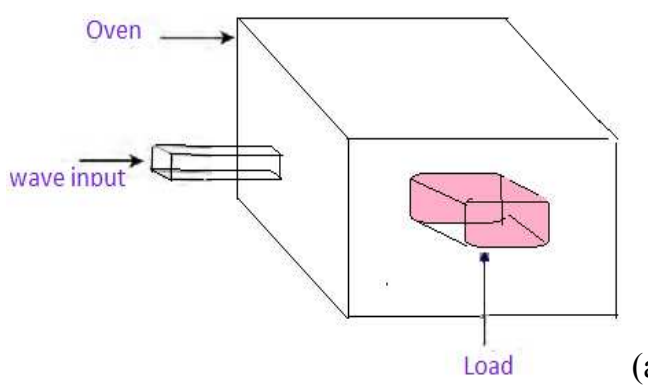

(a)

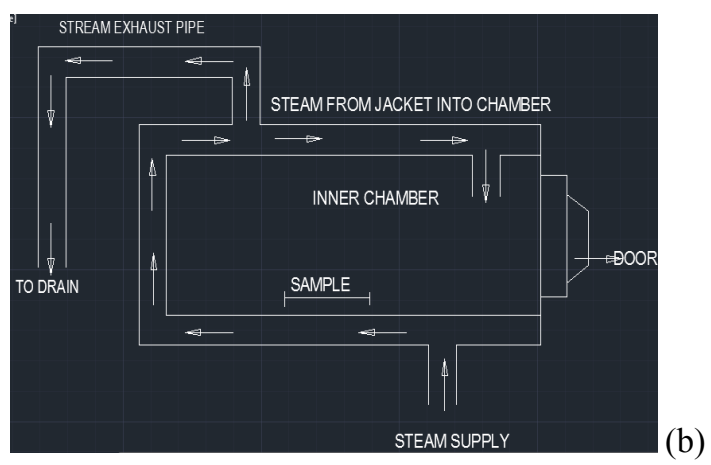

Figure $2 \boldsymbol{a} \& \boldsymbol{b}$. Schematic diagrams of microwave and autoclave systems, showing cylindrical shaped load placed in the center of the cavity.

Figure 2 a \& b show schematic components of microwave and autoclave systems for fabricating thermosetting polymer composites. The process consists of exposing the assemblage to a prescribed cure temperature cycle, which transforms the soft filler-resin mixture to a structurally hard product. The dominant physical phenomena involved in the cure process 
are (a) the chemical reactions affecting the curing process (b) the electromagnetic and conventional energies associated with the heating of the filler/ resin mixtures, including heat of the exothermic cure reaction

\section{Kinetic Model for Curing}

Unsaturated polyester resins are commonly used matrix for particulate reinforced composites. Commercial systems are generally supplied as relatively low molecular, unsaturated linear polyesters dissolved in a polymerizable monomer such as styrene, providing cross-linking units by reacting with unsaturation of the resin in a radical addition reaction. The complex chemistry of the unsaturated polyester reactions has been reported in literature [14] [15]. First, the initiator is decomposed leading to the formation of free radicals which progressively reduce the inhibitor concentration. The cure reaction are activated only when the inhibitor is exhausted (induction time); polyester and styrene radicals are first formed and then larger sized active molecules are generated. Finally, the termination reactions progressively reduce the active radical concentration and consequently the polymerization rate.<smiles>COCC=CCOC(=O)c1ccc(C(C)=O)cc1</smiles>

(a) Uasatuated polyester with active $\mathrm{C}=\mathrm{C}$ sie (*)

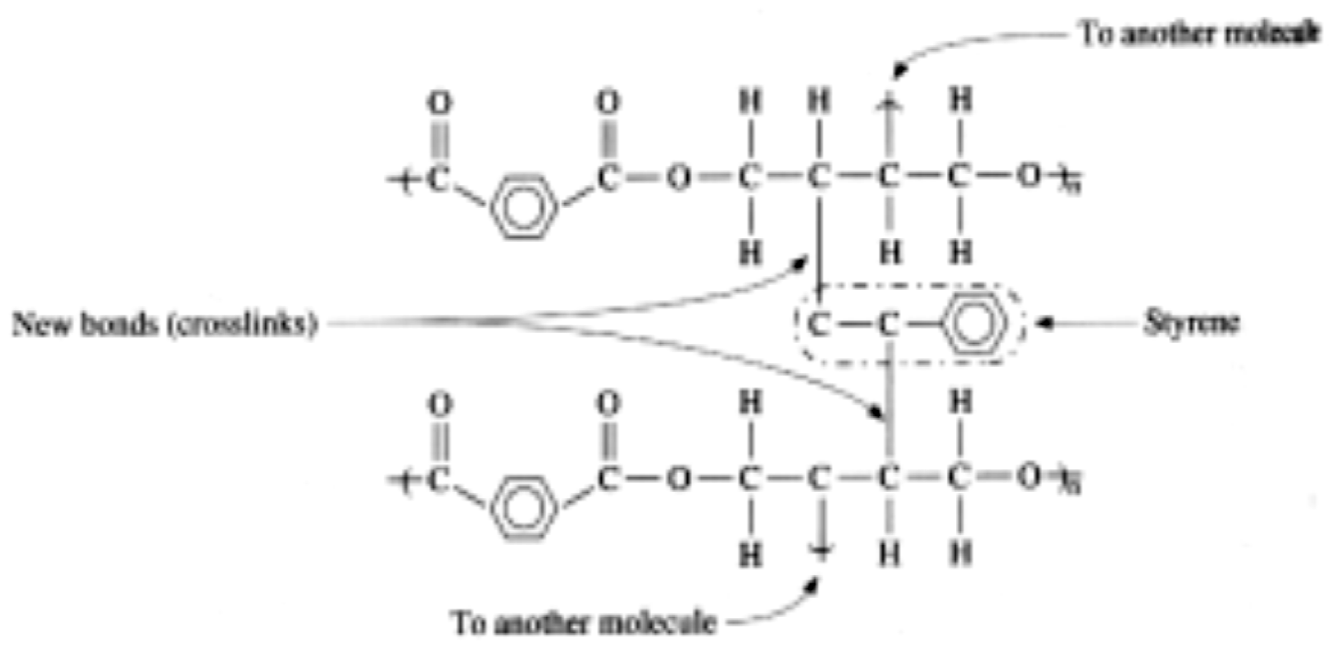

(b) Cowslinking of uncaurasod polyester

Source: [14] [15]

Figure 3 (a). Reaction chain between $\mathrm{C}_{2} \mathrm{H}_{2}$ molecule reacting with free hydroxyl radical (OH) from the $\mathrm{H}_{2} \mathrm{O}_{2}$ initiator (b) cross linking of unsaturated polyester.

Kenny and Trivisano [16] and Barton [17] have studied the kinetic of the curing reactions of thermosetting polyester by means of differential scanning Calorimetry (DSC), the degree of cure can be modeled simply as an autocatalytic reaction described by the Gonzalez- Romero relationship [18]. It is the most widely used and describes free radical polymerization [19] [20-21]. It is expressed as;

$$
\frac{d \alpha}{d t}=K \alpha^{m}(1-\alpha)^{n}
$$

Kamal [22] and Han et al [23] proposed a slightly more complex kinetic model

$$
\frac{d \alpha}{d t}=K_{1}+K_{2} \alpha^{m}(1-\alpha)^{n}
$$

Where $\mathrm{K}_{1}$ and $\mathrm{K}_{2}$ are rate constants given by

$$
\begin{gathered}
K_{i}=A_{i} \operatorname{Exp}\left(\frac{E_{i}}{R T}\right) \\
\mathrm{i}=1,2,3,4
\end{gathered}
$$

Also, $\mathrm{A}$ is the pre-exponential factor, $\mathrm{E}$ is the activation energy and $\mathrm{R}$ is the gas constant, $\mathrm{m}$ and $\mathrm{n}$ are constant which are independent of temperature.

\section{Thermal Model for Curing}

The thermal models consist of solving the energy equations in cylindrical coordinates for the temperature distribution in the laminates cross section. The governing equations for microwave and autoclave heating, for one dimensional heat 
transfer, also account for the heat generation due to the exothermic cure reaction in the composites may be written in the form developed by Chen et al [24] and Bejan [25] respectively.

$$
\begin{gathered}
\frac{\partial T}{\partial t}=\left\{\left(K f \mathrm{E}^{2} \mathcal{\varepsilon}^{\prime}(T)\right) \frac{\tan \delta(T)}{\rho C p}\right\} \\
\rho C_{p} \frac{\partial T}{\partial t}=K \frac{\partial^{2} T}{\partial x^{2}}+\rho \frac{\partial H}{\partial t}
\end{gathered}
$$

Note: In microwave heating, the specific heat terms show that thermodynamic transitions such as the glass transition temperature and melting of the material will greatly affect the heating susceptibility of the material [26]. The derivation of equation (4) also assumes that convection, conduction losses and heat flux due to chemical reactions are ignored. Equations (4 and 12) are useful for judging the effect of electrical properties on microwaves power absorption.

The heat generated by the curing resin, $\frac{\partial H}{\partial t}$ is calculated within the simulation according to equation (6), which assumes that that the heat released by the resin is proportional to the change in the resin's degree of cure $\frac{d \alpha}{d t}$ as expressed in equation 1. The fractional change in degree of cure is multiplied by the resin's total heat of reaction $\left(H_{r}\right)$. The result is then weighted by the mass fraction of the resin within the composite $\varphi_{\mathrm{r}}$.

$$
\frac{\partial H}{\partial t}=\phi_{r} H_{r} \frac{d \alpha}{d t}
$$

In order to build up the thermal models for the cure in microwave and autoclave, the assumptions are:

1. Negligible temperature change during flow

2. Homogeneous and well mixed reaction is achieved

3. Temperature and degree of cure are functions of time and direction normal to the part surface.

4. The composite is an infinite medium and can therefore be assumed to be one dimensional.

5. There is constant mould-wall temperature through the entire wall.

6. One dimensional heat conduction, the laminate thickness is small compared to the other dimensions.

7. The composite thermal conductivity $\mathrm{K}$ in the direction perpendicular to the planes of the laminate is computed using Halpin-Tasi equation [12]

$$
K=K_{r}\left\{\frac{\left(1-B_{1} B_{2} \varphi\right.}{\left(1-B_{1} \varphi\right.}\right\}
$$

Where

$$
B_{1}=\left\{\frac{\left(K_{f} / K_{r}-1\right)}{\left(K_{f} / K_{r}+B_{2}\right.}\right\}
$$

$$
B_{2}=\left\{\frac{1}{(4-3)(1-\varphi}\right\}
$$

1. The experimental evidence, more over suggested that there is no variation in these properties with the temperature or degree of cure

2. The density $(\rho)$ and the specific heat $\left(C_{p}\right)$ are computed as proper averages of single resin and filler property values as follows,

$$
\begin{gathered}
\rho_{c}=(1-\varphi) \rho_{r}+\varphi \rho_{f} \\
C p_{c}=\left\{\left(\frac{\rho_{r}}{\rho(1-\varphi)} C p_{r}+\frac{\rho_{f}}{\rho \varphi} C p_{f}\right)\right\}
\end{gathered}
$$

Where $c, r$ and $f$ are composite, resin and filler respectively.

3 . the power absorbed per unit volume varies linearly with the frequency $(f)$, relative dielectric constant $(\varepsilon)$, loss tangent $(\tan \delta)$ and the square of the electric field $(E)$ as expressed by Sutton [27],

$$
P=K f \mathrm{E}^{2} \varepsilon^{\prime} \tan \delta
$$

4. The depth of penetration of microwave $\left(D_{p}\right)$ at which the incident power is reduced by half is; [27]

$$
D p=\left(\frac{4.8}{f}\right) \sqrt{\frac{\varepsilon^{\prime}}{\varepsilon^{\prime \prime}}}
$$

Where $\varepsilon$ ' = Dielectric Constant, $\varepsilon "=$ Dielectric loss factor, $f$ =frequency where $\varepsilon$ ' and $\varepsilon$ " can be dependent on both frequency and temperature, the extent of which depends on the composite sample [27].

The relative dielectric constant and the loss tangent are the parameters that describe the behavior of a dielectric material under the influence of the microwave field. $\varepsilon$ ' mostly determines how much of the incident energy is reflected at the air - sample interface, and how much enters the sample. Tan $\delta$ predicts the ability of the material to convert the incoming energy into heat. During heating, the relative dielectric constant and loss tangent change with temperature.

5. All material properties (specific heat, density) are constant during the curing process.

6. Deformation of the material is negligible

7. No convection and conduction of heat.

\subsection{Numerical Analysis for Microwave Heating}

For the numerical solution of the mathematical model presented in equations (1), (4) and (6), the structure of the model can be summarized as follows:

1. Equation (4) was discretized using forward finite differences [28]

2. At each time interval the value of $d q / d t$ is computed from equation (6) by using Runge-Kuta method.

The following initial conditions were used in the model: $t=0 ; \alpha=\alpha_{0} ; T=T_{0} ; t \geq 0 ; T=T_{c}$ 
Note: initial temperature below $15^{\circ} \mathrm{C}$ will impede the curing process. The ideal temperature ranges from $25^{\circ} \mathrm{C}-35^{\circ} \mathrm{C}$ which should be maintained in the laminate.

Where $T_{o}$ and $T_{c}$ are the initial temperature and curing temperature respectively. The model was solved using MATLAB ${ }^{\circledR}$ Computer programming language.

\subsection{Numerical Analysis for Autoclave Heating}

For the numerical solution of the mathematical model presented equations (1) (5) and (6), the structure of the model can be summarized as follows:

1. Equation (5) is discretized using forward finite differences, summarized by Mathew and Fink [28]

2. At each time interval, the value of $\frac{d \alpha}{d t}$ is computed from equation (6) by using Runge Kutta method. These models were solved by MATLAB ${ }^{\circledR}$ Computer programming language version 10.1 .

The following initial and boundary conditions respectively are used in the model

$$
\begin{gathered}
\theta(0, x)=1 \\
\alpha(0, x)=10^{-8} \\
\theta(t, 1)=\theta_{m}=\frac{T_{m}}{T_{0}} \\
\frac{\partial \theta}{\partial t}=0, \text { for } x=0
\end{gathered}
$$

\begin{tabular}{|c|c|c|c|}
\hline Property (o) & unit & System A & System B \\
\hline Density & $\mathrm{Kg} / \mathrm{m}^{3}$ & 1860 & 1650 \\
\hline Weight fraction (wt) & $\%$ & 30 & 30 \\
\hline Specific heat Capacity $\left(\mathrm{C}_{p}\right)$ & J/Kg. K & 1460 & 1350 \\
\hline Heat of reaction $\left(\Delta \mathrm{H}_{\mathrm{r}}\right)$ & $\mathrm{J} / \mathrm{g}$ & 280 & \\
\hline Activation Energy $\left(E_{\mathrm{a}}\right)$ & $\mathrm{KJ} / \mathrm{mol}$ & 140 & 140 \\
\hline Reaction kinetic constant $(\mathrm{k})$ & $\operatorname{Sec}^{-1}$ & 8.9 & 8.9 \\
\hline Reaction order (n) & & 1.35 & 1.30 \\
\hline Reaction order (m) & & 0.65 & 2.7 \\
\hline Arrhenius Constant $(A \mathrm{r})$ & & $1.22 \times 10^{14}$ & $1.22 \times 10^{14}$ \\
\hline Tangential loss $(\operatorname{Tan} \delta)$ & & 0.00037 & 0.000303 \\
\hline Electric field strength $(£)$ & & $2.0 \times 10^{4}$ & $2.5 \times 10^{4}$ \\
\hline Constant (K) & $\mathrm{f} / \mathrm{m}$ & $55.61 \times 10^{-12}$ & $55.61 \times 10^{-12}$ \\
\hline Applied frequency (f) & $\mathrm{GHz}$ & 2.45 & 2.45 \\
\hline Dielectric Loss Factor ( $(\varepsilon ")$ & & 0.001 & 0.001 \\
\hline Dielectric constant $\left(\varepsilon^{\prime}\right)$ & & 2.68 & 3.032 \\
\hline Power dissipation $(\mathrm{P})$ & $\mathrm{W} / \mathrm{M}^{3}$ & 1 & 1 \\
\hline Curing cycle Temperature (Tc) & ${ }^{0} \mathrm{C}$ & 106 & 120 \\
\hline
\end{tabular}

Table 1. Assumed Physical-Chemical parameters used as input data for the model of the Microwave Heating.

\begin{tabular}{|c|c|c|c|}
\hline Property & Unit & $\begin{array}{l}\text { Polyester- } \\
\text { Aluminum } \\
\text { composite }\end{array}$ & $\begin{array}{l}\text { Polyester- } \\
\text { Carbon black }\end{array}$ \\
\hline Density $(\rho)$ & $\mathrm{kg} / \mathrm{m}^{3}$ & 1860 & 1650 \\
\hline Weight fraction (wt) & $\%$ & 30 & 30 \\
\hline Specific Heat capacity $\left(C_{p}\right)$ & $\mathrm{J} / \mathrm{kg} . \mathrm{K}$ & 1460 & 1400 \\
\hline Thermal Conductivity $(\chi)$ & $\mathrm{W} / \mathrm{m} \cdot \mathrm{K}$ & 0.169 & 0.172 \\
\hline Heat of reaction $\left(\Delta \mathrm{H}_{\mathrm{r}}\right)$ & $\mathrm{J} / \mathrm{g}$ & 285.7 & 283.8 \\
\hline Activation Energy $\left(E_{\mathrm{a}}\right)$ & $\mathrm{kJ} / \mathrm{mol}$ & 42.5 & 54.2 \\
\hline Arrhenius Constant $(A \mathrm{r})$ & $\mathrm{S}-{ }^{1}$ & 2991.4 & 5995 \\
\hline Kinetic Constant (k) & $\mathrm{s}^{-1}$ & 2950 & \\
\hline Reaction Order (n) & & 1.66 & 1.23 \\
\hline Reaction Order (m) & & 0.34 & 0.71 \\
\hline $\begin{array}{l}\text { Maximum temperature of } \\
\text { the reaction }\left(\mathrm{T}_{\max }\right)\end{array}$ & ${ }^{0} \mathrm{C}$ & 95 & 95 \\
\hline
\end{tabular}

Table 2. Assumed Physical-Chemical parameters used as input data for the model of the Autoclave Heating.

\section{Discussion of Results}

\subsection{Comparison of Cure Characteristic Between the Microwave and Conventional Heating for Polyester- Aluminum Composite and Polyester-Carbon Black Composites}

Cure characteristic measures the cure response of the samples to increase heat input through the cure cycle [1]. It is the measurement that is usually contrasted with a reference sample. It essentially provides data about the exothermic and endothermic reactions taking place by monitoring the amount of heat added or extracted from the samples to maintain a cure temperature. Points of measureable heat flows indicate the phase transitions of the material. Figure $3 a$ and $b$ show the plots of microwave and conventional curing degree of cure $(\alpha)$ as a function of time for the polyester-aluminum and polyester-carbon black composites. From these plots, the cure cycles for both microwave and conventional methods were obtained. The cure cycles were obtained from the curing time when the samples reached the ultimate degree of cure $(\alpha)$. The plots show that the microwaves cure reaction occurred at very fast rate compared to the conventional cure. These results are in agreement with those found in literatures [26] [29-32] where it has been suggested that direct molecular excitation by microwave irradiation greatly shortened the curing time. In the curing of composite panels, microwave radiation heats polymer molecules directly because of the relaxation of the polarized polymer dipoles along the electric field. Thus, the local molecular temperature, which was the effective temperature for the polymerization reaction would be higher in microwave heating than in conventional heating resulting in faster reaction rate in microwave heating [32]. Another reason is that, in conventional heating, heat transfer is very slow because of poor thermal conductivity of the resin.

With reference to previous publications on modeling of microwave and conventional heating of the polyester based 
aluminum and carbon black composites as a production process [1] [33], polyester aluminum composite in microwave and conventional heating were able to attain ultimate cure at approximately 20 minutes and 58.2 minutes respectively.

Table 3. Cure cycles for different Processing Method of Polyester-Aluminum and Polyester-Carbon black.

\begin{tabular}{|c|c|c|c|}
\hline Processing Method & $\begin{array}{l}\mathbf{T}_{\text {cure }} \\
\left({ }^{0} \mathrm{C}\right)\end{array}$ & $\begin{array}{l}\text { Actual Cure } \\
\text { Cycle (min) } \\
\end{array}$ & $\begin{array}{l}\text { Ultimate } \\
\text { Cure (\%) }\end{array}$ \\
\hline Microwave (Polyester-Aluminum) & 106 & 20 & 99 \\
\hline Conventional (Polyester-Aluminum) & 95 & 58.2 & 95 \\
\hline Microwave (Polyester-Carbon black) & 120 & 50 & 98 \\
\hline $\begin{array}{l}\text { Conventional (polyester-Carbon } \\
\text { black) }\end{array}$ & 99 & 66.6 & 98 \\
\hline
\end{tabular}

Figure 4 also shows that similar ultimate degree of cure was obtained for the sample (polyester-aluminum composite) regardless of method of curing (99\% in microwave and $95 \%$ in conventional)

Similarly, carbon black composite in microwave and conventional heating was able to attain ultimate cure at approximately 50 minutes and 66.6 minutes. Also, ultimate degree of cure for the sample, regardless of the method of curing was $98 \%$.
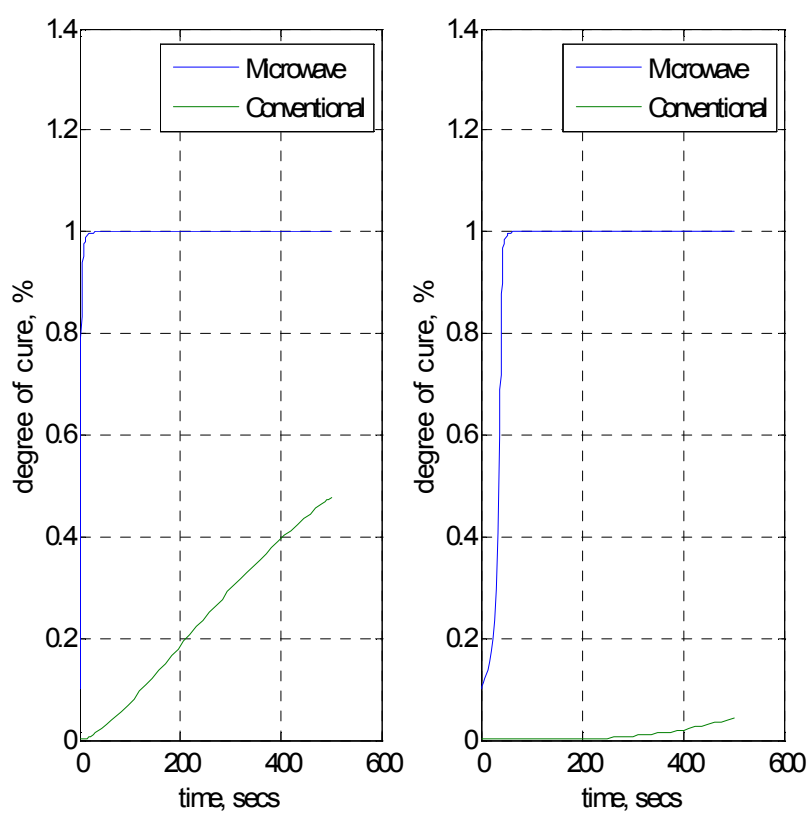

Figure 4a. Degree of Cure of Polyester-Aluminum Composite for Microwave and Conventional Heating Methods (4b) Degree of Cure of Polyester-Carbon black Composite for Microwave and Conventional Heating Methods.

\subsection{Comparison of Temperature Profiles Between the Microwave and Conventional Heating for Polyester- Aluminum Composite and Polyester-Carbon Black Composites}

Temperature control and heating rate show the responses of the systems in the curing process to heat as a function of time. It also determines the achievement of temperature stability and uniformity of heating with composites samples. The temperature profiles during the curing were monitored inside the samples for both microwave and conventional curing.
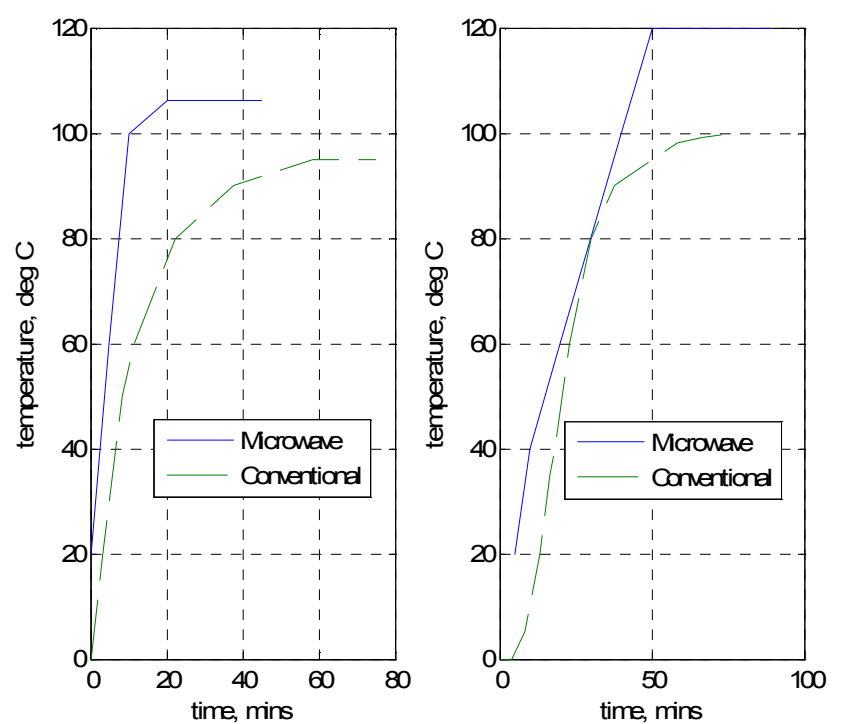

Figure 5a. Temperature Profile of Polyester-Aluminum Composite for Microwave and Conventional Heating Methods (5b) Temperature Profile of Polyester-Carbon black Composite for Microwave and Conventional Heating Methods.

Figure $5 \mathrm{a}$ and $\mathrm{b}$ show the temperature profile of the samples during the curing. From these figures, the temperature profile for the microwave curing shows much higher heating rate and the curing temperatures were reached at 20 minutes and 50 minutes for both polyester-aluminum and polyester-carbon black respectively. As for conventional curing, the average time required to attain the cure temperature were 58.2 minutes and 66.6 minutes respectively for the two systems. The vast difference in heating rate between the two curing methods was due to thick impermeable skin formed at the surface of the sample during conventional curing, thus preventing heat penetration [34].

In figure $4 a$ and $b$, at the initial stage of about 10 minutes of curing, there was a sharp increase in the heating rate for microwave curing compare to the conventional curing. This most possible due to heat released from the high chemical reactivity of the functional groups and more heat generated from dielectric heating [3]. The dielectric heating effect is likely to be greater in the early stages of reaction as the concentration and mobility of the dipoles in the resin is higher [3]. The heating rate increases steadily thereafter, which indicated that, as the cross linking progresses (the systems gelled and then vitrified), the mobility of the dipoles became more restricted, resulting in a reduction of dielectric heating [3]. At the later stage of the heating, the temperatures were maintained after the cure temperatures were attained. At that stage, the samples were cured and the temperature profile decreases gradually. The decrease suggested that the samples become less lossy (less interaction between electric field and dipolar molecules) [3].

Figure 5 in microwave curing, the temperature for both 
systems were maintained at $106^{\circ} \mathrm{C}$ and $120^{\circ} \mathrm{C}$ without any overshot. This indicated that the process control developed for the microwave power system was able to achieve temperature stability and uniform heating in the composite sample. This is better compared to conventional method of curing. This is better temperature control in microwave curing than conventional curing.

\section{Conclusions}

- Better control of temperature was observed during the microwave curing of both composite systems as compared to the conventional curing

- The two systems reached ultimate cure faster in microwave curing than conventional curing showing that rigid temperature control measures must be developed for the production of both composites to suite their cure characteristics

\section{References}

[1] Adeodu A. O., Anyaeche C. O., Oluwole O. O., 2014. Modeling of Microwave Curing of unsaturated Polyester Based Composite materials as Process guide. Journal of Advancement in Engineering and Technology. 1(1).

[2] Carlone P., Palazzo G. S., 2008. Numerical modeling of the microwave assisted pultrusion process. Mathematical and Computation Modeling,Vol. 53.

[3] Yussoff R., Aroua M., Nesbitt A.and Day R. J., 2007. Curing of polymeric composite using microwave resin transfer moulding (RTM). Journal of Engineering Science and Technology. Vol. 2, 151-163.

[4] Methven J. M., Ghaffariyan S. R., Abidin A. Z., 2000. Manufacture of fibre-reinforced composites by microwave assisted Pultrusion, Polymer Composite, 21, 586-594.

[5] Sutton W. H., and Clark D. E.,1996. Microwave processing of materials, Annual Review of Material Science. Vol 26, 299-331.

[6] Adan A. Abdul Rasak, Ali M. Hameed, Saad R. Sultan 2011. Modeling of the cure of Epoxy based composite heated at constant temperature in cylindrical mould. Diyala Journal of Engineering Science. Vol. 4, 1-11.

[7] Progelhof R. C., Throne J. L., 1975. Non-isothermal curing of reactive plastics. Polymer Engineering Science. Vol.15, 690695.

[8] Pusatcioglu S. Y., Hassler J. C., Fricke A. L., and. Mcgee H. A., 1980. Journal of Apply Polymer Science, 25, 81-93.

[9] Nixon J. A and Hutchinson J. M., 1985. Analysis of the cure of sheet moulding compound. Development of the Model. Plastic and Rubber Processing Application, 5, 349-357.

[10] Hutchinson J. M and Nixon J. A., 1985. Analysis of the cure of sheet moulding compound 1. Application of the model to various molding geometries. Plast. Rubb. Proc. Appl., (5), 359363.

[11] Dave R., Kardos J. L. and Dudukovic M. P., 1987. Journal of Polymer Composites. 8, 29.
[12] Halpin J. C., Kardos J. L., and Dudukovic M. P., 1983. Pure \& Appl. Chem. 55, 893-906.

[13] Kwok Yeung Peter Wong, 2012. Measurement of mechanical electrical and thermal properties of glass powder reinforced epoxy composites. A MSc dissertation. University of Southern Queensland. Australia.

[14] Kenny J. M., Apicella A., and Nicolais L. A., 1989. Poly. Eng. Sci., 9, 973-983.

[15] Kenny J. M., Maffezzoli A, and Nicolais L., 1990 "A model for the thermal chemo-rheological behavior of thermoset processing (II) unsaturated polyester based composites", Composites Science and Technology, 38, 339-358,

[16] Kenny J. M. and Trivisano A., 1991. Polymer Engineering and Science. 31, 1426.

[17] Barton J. M., 1985 "The application of differential scanning calorimetry (DSC) to the study of epoxy resin curing reaction", Advance Polymer Science Vol. 72, 111-154.

[18] Gonzalez-Romero V. and Casillas N., 1989. "Polymer Engineering and Science" Vol. 29, 5.

[19] Kosar V and Gomzi Z., 2001."Thermal effects of cure reaction for unsaturated polyester in cylindrical Moulds", Chem. Biochem. Eng., 15(3), 101-108.

[20] Lam W. K., Plaumann H. P., and Tran T., 1990."An Improved kinetic model for the autocatalytic curing of styrene-based thermoset resins.", Journal Applied Polymer, 41, 3043- 3057.

[21] Lee W. I and Springer G. S 1984. Journal of Composite Material.18, 387.

[22] Kamal M. R. and Sourour S., 1973. "Kinetics and thermal characterization of thermoset cure", Polymer Engineering and Science, 13(1), 59-64.

[23] Han C. D., Lee D. S., and Chin H. B., 1986. Journal of Polymer Engineering and Science.26, 393-404.

[24] Chen M., Siochi E.J., Ward T.C and McGrath J. E., 1993. Journal of Polymer Engineering and Science. 33,1092.

[25] Bejan and Adrian 1990. Heat Transfer, John Wiley and Sons, New York.

[26] Suckley, D.R. 2000. Microwave Processing of the Araldite LY5052:HY5052 Epoxy Resin System. M. Sc. Dissertation. UMIST, United Kingdom.

[27] Sutton, W.H., 1989. Microwave Processing of Ceramics, Ceramic Bulletin, 68(2), 376-86.

[28] Mathews J. H., and K. D. Fink, 1999. Numerical Methods Using MATLAB. 3rd Ed., Prentice Hall.

[29] Katakura Y., 2001. Microwave Curing of Curing of Diglycidyl Ether of Bisphenol A/4-cyclohexane-1, 2-dicarboxylic Anhydride Resin System. M. Sc. Dissertation. UMIST.

[30] Zhou J., Shi C., Mei B., Yuan R., Fu Z., 2003. Research on the Technology and Mechanical properties of the Microwaves processing of polymer. Journal of Material Processing Technology. Vol. 137(156-158).

[31] Boey F. Y. C., Yap B. H., Chia L., 1999. Microwave curing of epoxy-amine system - Effect of curing agent on the enhancement. Polymer Testing. Vol. 18, 93-109. 
[32] wei J., Hawley M. C and Demeuse M. T., 1995. Kinetics modeling and time- temperature-transformationdiagram of microwave and thermal cureepoxy resin. Polymer Engineering and Science. Vol 35(6), 461-470.

[33] Adeodu A. O., Anyaeche C. O., Oluwole O. O., Afolabi S. O.,2015. Modeling of Conventional Autoclave Curing of Unsaturated Polyester Based Composite Materials as Production Process Guide. International Journal of Materials
Science and Applications. Vol. 4, No. 3, 2015, pp. 203-208. doi: 10.11648/j.ijmsa.20150403.18.

[34] Philip C.Sturman and Rexford N. Y., 1999. Induction heating of Polymer matrix composite fibre strands. SAMPE Journal, Vol. 26, No 4. 